\title{
La juventud campesina en los programas de Acción Cultural Popular*
}

\author{
Nurys Esperanza Silva Cantillo' \\ Universidad Nacional de Colombia
}

Recibido: marzo 20 de 2014 - Revisado: mayo 26 de 2014 - Aceptado: junio 20 de 2014

Referencia para citar este artículo: Silva-Cantillo, N. E. (2014). La juventud campesina en los programas de Acción Cultural Popular. Revista Cientifica Guillermo de Ockham, 12(1), 51-63

\section{Resumen}

Este artículo es un análisis de las publicaciones del semanario El Campesino entre los años 1958 y 1990. El Campesino fue el medio de difusión de Acción Cultural Popular que gracias a la cooperación internacional y al apoyo de las políticas públicas nacionales logró consolidarse como el proyecto de educación radial más importante de América Latina. El estudio revela cómo las comunicaciones de prensa intentaron por una parte, mantener la población rural al margen de las ideas socialistas en boga y por la otra, difundir los ideales y comportamientos que deberían llevar a cabo los campesinos en su vida cotidiana a fin de contribuir al desarrollo de Colombia. Los resultados muestran que la configuración de esta clase trabajadora se forjó a base de consignas tales como el incremento de la productividad, las nociones de higiene, el consumo de productos, la migración y la colonización. Esta clase trabajadora, de manera paradójica, es al mismo tiempo un grupo subordinado y subsidiario de la economía y protagonista del desarrollo. Los programas difundidos a través de El Campesino muestran cómo bajo la noción de progreso se consolidaron visiones diferenciales de la juventud y la ciudadanía en el país. Si bien entre las poblaciones urbanas la ampliación del periodo educativo y la construcción de espacios de ocio para los jóvenes eran sinónimo de adelanto, en el campo estos fueron considerados mera "fuerza de trabajo" disponible para la tecnificación de las labores agrícolas, la colonización de tierras baldías y el desarrollo de la industria para el progreso nacional.

Palabras clave: Juventud campesina, programas de desarrollo, medios de comunicación.

\section{The rural youth en los programs Action Cultural Popular}

\section{Abstract}

This paper is an analysis of the publications of the weekly El Campesino between 1958 and 1990 . This newspaper was the means of dissemination of Popular Cultural Action through international cooperation and support of national public policies as the project was able to consolidate most important radial education in Latin America. The study reveals how press releases tried first, keep the rural population outside of socialist ideas in vogue and on the other, spread the ideals and behaviors that should carry out the peasants in their daily lives to contribute to the development of Colombia. The results show that the configuration of this working class was forged based on slogans such as: Increasing productivity, notions of hygiene, product consumption, migration and colonization. This working class,

* Este artículo es producto del proyecto de investigación Jóvenes y oficios en la zona rural. Un análisis sobre formación de ciudadanias, progreso y cambio sociocultural entre los campesinos del Valle de Tenza.

1. Antropóloga y Magíster en Antropología de la Universidad Nacional de Colombia. Actualmente forma parte del grupo de antropología social del Instituto Colombiano de Antropología e Historia. Favor dirigir correspondencia a la calle 148 No 13B - 28 Apto 301 de Bogotá. E-mail: nesilvac@ unal.edu.co. 
paradoxically, is both a subordinate and subsidiary group of the economy and character development. Programs broadcast through El Campesino show how the notion of progress under differential visions of youth and citizenship in the country were consolidated. While among urban populations expanding the educational period and the construction of places of entertainment for the young were synonymous with the advancement in the field these were considered mere "labor power" available to the modernization of farming, the colonization of badlands and the development of the industry to national progress.

Keywords: Rural youth, development programs, media.

\section{Introducción}

Durante la segunda mitad del siglo XX, los programas y las políticas públicas en Colombia persiguieron a toda costa la inclusión de los campesinos en el desarrollo de la nación. La promoción de la educación y el incremento de la productividad, particularmente, fueron las bases sobre las cuales se sustentó la transformación de sus condiciones de vida y el propósito de hacerlos ciudadanos.

Bajo la figura de las escuelas radiofónicas, los programas de Acción Cultural Popular (ACPO) lograron articular diversas formas de educación presencial y a distancia con el uso de variados medios de comunicación. Las letras, las matemáticas, la salud y la producción agropecuaria formaban parte de los contenidos que llegaban a las veredas mediante la radiodifusión.

Los conocimientos eran reforzados por los jóvenes que se formaban como líderes comunitarios en los institutos de dirigentes campesinos, quienes luego de una temporada de estudio en los internados debían regresar a sus veredas para complementar la instrucción de la radio con las cartillas de educación fundamental, la biblioteca popular y el periódico El Campesino, órgano a partir del cual se hace este análisis (Bernal, 2005; Banco de la República, 2012).

Aunque el principal objetivo de ACPO era la alfabetización, sus campańas educativas respondían a la coyuntura social y política que atravesaba Colombia a mediados del siglo pasado. En la década de 1950, la mayoría de la población del país era campesina y joven; las zonas rurales se caracterizaban por la inequidad en la distribución de la tierra y atravesaban condiciones de precariedad en cuanto al acceso a bienes y servicios. Esta década presentaba también un escenario de violencia bipartidista y de luchas campesinas por el acceso a la tierra.

Durante las décadas de 1930 y 1940, el campo colombiano se había caracterizado por la conformación de ligas campesinas o baluartes. Los levantamientos contra las haciendas y el surgimiento de las llamadas repúblicas independientes de Colombia hicieron pensar a Sánchez (1977) que Colombia era un Estado prerrevolucionario. Las condiciones sociales y políticas constituían el medio idóneo para la expansión comunista y convertían al país en un peligro internacional.

A mediados de siglo, los jóvenes de distintas latitudes protagonizaban movimientos sociales que se oponían al colonialismo, al capitalismo y a la inequidad (Vera de Flachs, 2006). En Colombia, los principales actores y víctimas del periodo conocido como la Violencia fueron jóvenes rurales (Guzmán, Fals-Borda \& Umaña, 2005), por lo tanto intervenir sobre ellos podía ser la clave para prevenir las amenazas revolucionarias y fortalecer los ideales del progreso.

En este contexto surgen las escuelas radiofónicas de Acción Cultural Popular, programa conocido como Radio Sutatenza que nació en 1948 y fue ideado por monseñor José Joaquín Salcedo en el sur de Boyacá. En la década de 1950 contó con el apoyo del Vaticano, la Unesco y la Cooperación Alemana para el Desarrollo (Bernal, 2005) y sus más de cuarenta años de funcionamiento hicieron de él la iniciativa de educación radial católica más importante de América Latina.

Durante la década de 1960, la ACPO articuló y promovió programas internaciones y nacionales ${ }^{2}$ (entre ellos la reforma agraria) que buscaban mejorar las condiciones de vida de los campesinos, pacificar la población y combatir el comunismo. Algunos como el Programa Interamericano para la Juventud Rural y los Cuerpos de Paz tuvieron un claro énfasis generacional y fueron aplicados en todo el continente. A continuación se presentan los enfoques y los programas más notorios dirigidos a los jóvenes rurales a través de El Campesino durante la segunda mitad del siglo XX.

Desde la Conquista y la Colonia la producción agrícola en América Latina fue subsidiaria de las economías extrac-

2. En el ámbito nacional, varias instituciones participaron de los proyectos ACPO: la Caja Agraria, el Instituto Colombiano Agropecuario (ICA), el Instituto de Mercadeo Agropecuario (Idema ), el Instituto Colombiano de Reforma Agraria (Incora), el Instituto Nacional de Recursos Naturales (Inderena), el Sena y el Instituto Colombiano de Bienestar Familiar (ICBF).

$52<$ Universidad de San Buenaventura, Cali - Colombia 
tivas. Tras el surgimiento de las repúblicas, la producción de bienes básicos continuó siendo un factor determinante para el abastecimiento interno y empezó a tener importancia para el establecimiento de relaciones comerciales con otras naciones, lo que se tradujo en una economía basada en la exportación de materias primas hacia las naciones industriales y la importación de manufacturas.

En este contexto general, el control sobre la tierra y la explotación de la fuerza de trabajo rural fueron indispensables para la instauración de los poderes económicos locales (Fajardo, 1981). Según Fals-Borda (1975), el campesinado surgió del mestizaje y la consolidación de una población libre sujeta a un sistema señorial, que no obstante gozaba de un amplio grado de autonomía debido a su condición de "libres" y a la doble participación en la producción para la autosubsistencia y el mercado.

Para Fals-Borda (1961) los campesinos sufrieron un violento proceso de aculturación durante la Conquista y la Colonia; sin embargo, Ortiz (1973) sostiene que aunque es cierto que América Latina vivió una imposición por la fuerza de normas culturales sobre la población nativa, lo que en realidad se presentó fue un proceso de transculturación en el que la toma selectiva y estratégica de significados y costumbres de las poblaciones española, indígena y negra se constituyó en la base cultural del campesinado.

\section{Método}

Este trabajo es resultado de una investigación cualitativa que incluyó la revisión documental y el análisis de archivo. Es de naturaleza descriptiva y se centra en el análisis intensivo y cualitativo de los archivos de prensa de Acción Cultural Popular entre 1958 y 1990. Para ello se consultaron distintas secciones del semanario El Campesino tales como editorial, información, conocimientos, entretenimiento, propagandas y una separata especial que resaltaba hechos de carácter nacional, religioso o institucional.

El Campesino fue un periódico de distribución nacional que a través de los programas de ACPo llegó a todas las regiones y veredas del país. Sus notas de prensa, además de informar sobre los acontecimientos nacionales e internacionales con énfasis en los eventos agrarios, estaban impregnadas de un matiz moral y educativo que instruía y aconsejaba a los campesinos en la vida cotidiana. Los archivos históricos de este medio de comunicación fueron consultados en el depósito de la hemeroteca de la Biblioteca Luis Ángel Arango, ubicada en la ciudad de Bogotá (Colombia).

\section{Resultados}

El análisis de los archivos de prensa de Acción Cultural Popular de los años 1958 a 1990 permitió identificar dos temas centrales y reiterativos: el combate al comunismo y el énfasis en la productividad agrícola como estrategia para elevar el nivel de vida de la población rural. El trabajo duro y no la revolución, permitiría al campesino superar la pobreza.

Si bien los programas intentaron hacer de los campesinos nuevos ciudadanos y actores principales del desarrollo, delegaron sobre la población rural un papel esencialmente productivo y crearon un imaginario de sus habitantes como sujetos económicos. En este sentido, la población rural formó parte de una configuración de la clase trabajadora que sería a la vez un grupo subordinado y subsidiario de la economía y un protagonista del progreso.

\section{El trabajo: una estrategia moral contra el comunismo}

En los programas, el incremento de los rendimientos agrícolas solo era posible a partir de la transformación de los sujetos. Con frecuencia, los campesinos eran representados como una población ruda, primitiva y poco productiva, como lo atestiguan algunas de las campañas publicitarias que aparecían en el periódico y mostraban el impacto de ACPO en la transformación de la población rural: "Yo antes era un campesino rudo y lleno de pura pereza; ahora voy adelante con mi Radio Sutatenza".

Esta afirmación que invadió las propagandas de divulgación de ACPO durante el año 1965, permite evidenciar no solo la intención de lograr el "adelanto" o el "progreso" para los campesinos, sino también las causas del atraso. El ocio, la rusticidad entendida como falta de tecnificación, el analfabetismo y el desconocimiento de las artes y las ciencias, fueron observados como factores principales de las precarias condiciones de vida de la población rural.

Además de la pobreza, la falta de educación y la conducta laboral del pueblo, la explosión demográfica amenazaba con empeorar las condiciones económicas y el "subdesarrollo" del país, situación observada también como un caldo de cultivo para la violencia y la expansión del comunismo. Controlar la reproducción e incrementar la producción a pasos agigantados era la solución para el futuro económico y político. Así, entre las notas de prensa se atacaban fuertemente tanto el comunismo como el ocio y la vagancia. 
El trabajo y el "progreso" de las clases populares eran considerados como la principal estrategia para prevenir una revolución. Los mensajes del periódico iban dirigidos al campesino ya en su vida pública ya en su vida privada. Como protagonista de la vida nacional, debía ser consciente de la incidencia de sus prácticas en el crecimiento de la economía colombiana, mientras los dirigentes y las instituciones del país se encargaban de generar las condiciones de progreso. En la vida privada debía transformar sus costumbres más íntimas para lograr sobresalir como individuo.

Dado que la pereza y la rusticidad conducían a la pobreza y esta a su vez llevaba a la violencia y la rebeldía, las campañas de ACPO se centraron en llevar el trabajo, la técnica, la cultura y una sana entretención a los campesinos para elevar sus condiciones de vida y mitigar los peligros de una revolución. Sus programas buscaban transformar al campesino iletrado en un campesino ilustrado que sin abandonar su condición de población trabajadora se identificara con los valores de la alta cultura.

En el ámbito nacional, el periódico mostraba la vida de un país agrario y hacía del campesino el principal actor del desarrollo. En la década de 1960, la publicación desplegaba de manera enfática las disertaciones del Congreso sobre las leyes de la reforma agraria y la alianza entre los poderes político y religioso para consolidar el surgimiento del agro colombiano. Ya que las clases dirigentes estaban centradas en proponer una reforma agraria integral, los campesinos debían empeñarse en lograr altos niveles de productividad en sus parcelas.

La prensa forjó un imaginario del atraso colombiano causado por el ocio: los campesinos eran holgazanes y debían ser "civilizados" (productivos). En el caso de las tierras, durante la década de 1960 y hasta 1972 (con el pacto de Chicoral) se llevó a cabo un fallido intento de reforma agraria. No obstante, la civilización y la productividad de los hombres sería una de las campañas que tendrían continuidad durante varias décadas.

En los años de 1960 y 1970, múltiples comunicaciones de prensa mostraban las exorbitantes sumas de dinero que el país perdía a causa de las débiles costumbres laborales del pueblo: "Cincuenta millones de pesos en pérdidas producen el ocio y el descuido diariamente", afirmaba un titular del periódico El Campesino de junio 3 de 1962. Estudios del Banco Internacional de Reconstrucción y Fomento (BIRF) conducidos por Lauchlin Currie, concluían que el "ocio nacional" lleva la ruina económica y a "las condiciones de miseria y subdesarrollo" que caracterizaban al país.
A partir de estos estudios surgieron las propuestas de cambio del calendario laboral, el cual era objeto de feroces críticas por contener un número insufrible de festivos y días de gracia (El Campesino, junio 3 de 1962). El problema de la improductividad persistió durante años y era común leer titulares que afirmaban: "Diez mil millones de pesos se pierden por el ocio" (El Campesino, mayo 4 de 1964). "El ocio estrangula la economía nacional" (El Campesino, marzo 28 de 1965). "Aumento progresivo de la delincuencia por ocio, alcoholismo y falta de cultura" ( $E l$ Campesino, marzo 7 de 1965). "El ocio y la delincuencia son fenómenos correlativos" (El Campesino, abril 5 de 1965). "Campaña contra el ocio" (El Campesino, julio 2 de 1967). En 1971, un titular de prensa describe a Colombia como "el país del gran ocio" y la nación aparece entre los países "líderes del ocio en el mundo" (El Campesino, febrero 7 de 1971).

Las causas de improductividad se explicaron en parte, con base en las prácticas laborales de los campesinos que ponían de presente el choque entre el trabajo y la satisfacción de necesidades por un lado, y la lógica de ganancia del capitalismo por el otro, lo que cuestionaba la supuesta racionalidad de este equilibrio:

En la actualidad, subrayó el presidente de la SAC (Sociedad de Agricultores de Colombia), el empleo del campesino es disfrazado, porque él, trabajando las dos terceras partes del tiempo, tiene lo suficiente para una subsistencia y por lo mismo no hay una reclamación agresiva de trabajo. Algunas masas campesinas se desplazan a los cultivos de café, algodón y de papa de manera estacional y con los salarios que allí perciben se sostienen hasta tres veces más del tiempo que han trabajado porque sus consumos son muy bajos. Esta situación, agrega el doctor González Matallana, es gravísima porque desde el punto de vista económico se desperdicia una importante fuerza productora y desde el punto de vista social, no se obtiene un mejor estar de las gentes (El Campesino, enero 25 de 1970).

El trabajo "disfrazado" o la falta de laboriosidad del campesino, era una situación a todas luces indeseable a la luz del modelo económico vigente que tenía al agro como el motor del crecimiento de la economía nacional. Según el modelo de sustitución de importaciones, la agricultura debía proporcionar los bienes básicos y una mano de obra de bajo costo a fin de potencializar el crecimiento de la industria y la ganancia de divisas. Al mismo tiempo, era una necesidad imperiosa la capitalización de la población rural para que sus miembros se convirtiesen en consumidores de los bienes manufacturados y de esta manera se dinamizara la economía interna (Johnston \& Mellor, 1962). 
Sin embargo, El Campesino denunciaba año tras año la insuficiencia de la producción agropecuaria nacional:

[Colombia] necesita 22 millones de huevos y sólo produce 5 millones. (El Campesino, noviembre 28 de 1971). Los campesinos son los únicos que trabajan la tierra y cuidan los animales que producen carne, leche y otras cosas necesarias para la vida, tienen por consiguiente que producir alimentos para el resto de la población colombiana que vive en las ciudades, o sea, 12 millones de personas. En otras palabras, cada campesino que trabaja tiene que producir para alimentar a cuatro personas incluyéndose él mismo y según cálculos que hacen los expertos, el rendimiento del trabajo de los campesinos, en promedio, apenas sirve para alimentar dos personas. Esta es una razón clara para explicar por qué la carestía de los alimentos y la pobreza y desnutrición que vive el campesino (El Campesino, mayo 14 de 1972).

Por lo tanto, los programas debían inculcar en la población agraria las nociones de productividad y consumo para lograr un crecimiento acelerado de la economía. Solamente el cambio generacional en el uso de nuevas técnicas y prácticas agrícolas podría generar las transformaciones necesarias para el crecimiento económico. Los jóvenes campesinos serían los actores destacados de estas transformaciones: "El joven campesino tiene que prepararse para producir más" (El Campesino, mayo 14 de 1972).

Los jóvenes constituían la población mayoritaria en términos demográficos y estaban fuertemente involucrados en las problemáticas de violencia que afrontaba el país a mediados de siglo. Además, la intervención sobre la juventud ya se había puesto a prueba en Europa a partir de la década de 1890, cuando el movimiento scout contribuyó a disminuir la delincuencia entre los jóvenes obreros de Inglaterra. La Iglesia católica conocía el funcionamiento de las organizaciones juveniles y había aplicado sus métodos en varias regiones de América Latina como medio para la evangelización, la incorporación de nuevos miembros a las comunidades religiosas y el ejercicio de la responsabilidad concedida por los Estados para la educación del pueblo (Muñoz, 2007). Las agrupaciones de jóvenes eran la forma común como estos se organizaban de acuerdo con las directrices de la Acción Católica (una forma de apostolado de divulgación evangélica, fundada según las pautas dictadas por el papa Pío XI y el Concilio Vaticano II), que para el caso de Colombia era objeto de atención especial dados los niveles que había alcanzado la guerra interna y la presión internacional de la que era objeto el Gobierno para combatir una posible revolución.

De acuerdo con esta lógica, ACPO se centraría, entonces, en la formación de líderes campesinos que fomentaran la moral del trabajo en las zonas rurales. Esta tarea tuvo enfoques diversos y fue objeto de cambios drásticos en la segunda mitad del siglo XX. Durante las décadas de 1960 y 1970, se fomentó de manera intensa el trabajo entre los jóvenes mediante formas de intervención centradas en la formación de dirigentes que lograran organizar de manera sistemática las masas campesinas a fin de que adoptaran una agricultura tecnificada y fomentaran la colonización de baldíos. Durante la década de 1970 continuaron los programas de formación de líderes; sin embargo, la colonización dejó de ser algo deseable debido a sus efectos sobre el conflicto armado y a la adopción paulatina de políticas ambientales.

A finales de la década de 1970 y durante el decenio de 1980, se dio un cambio decisivo en las formas de intervención sobre los jóvenes. Se difundieron nociones psicológicas modernas relacionadas con la adolescencia y la juventud y la normatividad internacional hizo desaparecer paulatinamente la antigua visión con respecto al trabajo de los menores (OIT, 1973). En su lugar, se enfatizó en la familia, la procreación responsable y la educación en valores. Durante este periodo, gracias al discurso de algunas instituciones (especialmente el Instituto Colombiano de Bienestar Familiar, creado en 1968) se dio una inversión en la relación generacional: se pasó de una juventud productora con padres patrones, a una juventud que debía ser educada y protegida, amén de ser receptora de los bienes y cuidados de la generación anterior. Sin embargo, en las zonas rurales este enfoque fue objeto de importantes contradicciones.

\section{Los clubes juveniles: tecnificación, higiene y consumo}

En los programas de ACPO, la educación no estuvo dirigida de forma exclusiva hacia los jóvenes; antes bien, tenía la finalidad de llegar a toda la población rural de Colombia. Sin embargo, la formación de dirigentes y clubes rurales para irrigar las nuevas técnicas y la cultura sí tuvo un claro enfoque generacional.

De otro lado, El Campesino promovía los cultivos más rentables como el algodón (el oro blanco), el café, la papa y el tomate, enseńaba a reconocer las plagas y el estado de la tierra en los cultivos, promocionaba la fabricación de abonos orgánicos para la las siembras de pancoger e incluía las campañas de la llamada Revolución verde para incorporar semillas mejoradas con alto nivel proteico y la compra de maquinaria, abonos y pesticidas de las industrias químicas que se promocionaban como parte de la cooperación internacional. Los jóvenes campesinos 
jugaron un importante papel en la incorporación de nuevas tecnologías, insumos agrícolas y artículos de consumo. Además de los bancos, varias industrias como Concentrados Apolo, Du Pont Colombia, Hoechst Colombia, Productos Fitosanitarios Colombia, Química Schering, Rohm and Haas Colombia, Sears Roebuck Colombia y Sandoz invertían en los clubes y grupos juveniles rurales para apoyar su formación productiva y el aprendizaje de nuevas técnicas agropecuarias (El Campesino, octubre 10 de 1976).

En el plano más íntimo, El Campesino instruía a la familia para lograr mayores rendimientos. Varias de las notas iban dirigidas a enseñar "cómo aprovechar bien el tiempo" y daba algunas claves: "Divida su tiempo en dos partes: tiempo para hacer lo que se debe y tiempo para hacer lo que desea". "Utilice una libreta para planear las obligaciones cotidianas" (El Campesino, 31 de agosto 1969). Separar el tiempo libre y el tiempo de trabajo era, igualmente, una oportunidad para dar una capacitación integral a la población y enseñar lo que debía hacer en cada momento. El tiempo de trabajo debía estar ocupado por las técnicas y las prácticas agrícolas y el tiempo libre un espacio para recibir instrucción y entretenerse "de forma sana”.

En el tiempo libre, la higiene y el entretenimiento formaron parte de los grandes esfuerzos de ACPO por llevar "la cultura" al pueblo e incrementar el consumo de los campesinos. Las campańas de higiene iban desde la instrucción en la forma correcta de preparar los alimentos y hervir el agua, hasta aquellas que enseñaban a cambiar letrinas por inodoros, usar jabón, vestir una pijama y calzar zapatos como "una necesidad" y no como "un lujo" ( $E l$ Campesino, julio 3 de 1960). Otras campañas se enfocaban en la pulcritud cotidiana: "La limpieza da salud y belleza"; "tenga limpia la cara"; "es mejor el cabello corto y aseado"; "use y tenga limpia la ropa interior", eran algunas de las primeras campañas de higiene publicadas en El Campesino desde 1960 hasta 1963. La higiene fue también el móvil principal de la publicidad. Con excepción de la cerveza y el tabaco, la publicidad se argumentaba como una medida educativa que buscaba mejorar las condiciones de vida de la gente que para el momento era la población mayoritaria del país y representaba una población "rústica", pero con un gran potencial de consumo. La ropa, los zapatos, el jabón y los sanitarios fueron los principales objetos de venta. La imagen del maestro con sus alumnos de escuela o las fotografías de jóvenes campesinos en la publicidad eran centrales en la promoción de la higiene y la compra de nuevos productos.

Además de estimular y promover el consumo y las conductas higiénicas, en el campo se carecía de fuentes para generar un entretenimiento sano. En este sentido, ACPO se encargó del asunto mediante campańas que facilitaran el acceso del pueblo a la cultura. El cambio de "un libro por un huevo" o los eventos especiales para llevar el cine a las comunidades rurales fueron algunos de sus programas. La instrucción sobre cómo crear trajes, historias y personajes para teatro, los comics, los "campesigramas" y las novelas como Rosalinda la del río y Margarita, un amor sobre el valle, cuyos capítulos eran publicados cada semana en la sección recreativa del periódico, buscaban ocupar el tiempo libre de la población e inculcar valores católicos. La educación en técnicas artesanales y la alfabetización a través de la radio también eran formas productivas de ocupar el tiempo libre.

Los jóvenes fueron los mediadores de la difusión de los programas de ACPO. Cerca de quinientos muchachos eran becados semestralmente para formarse como dirigentes campesinos en los internados de los institutos de formación de líderes. Tras culminar su educación, debían regresar a sus comunidades e implementar lo aprendido. Los jóvenes llevaban a cada una de las veredas del país la Radio Sutatenza y apoyados en las cartillas y el periódico llevaban a cabo tareas de alfabetización, hacían campañas de salubridad e higiene, enseñaban contabilidad e instruían en distintos oficios como modistería, ebanistería, mecánica y nutrición, entre otros. Asimismo, debían promover la creación de empresas agropecuarias y enseñar las formas de acceder al crédito así como las técnicas agrícolas.

Los deportes y el ajedrez fueron actividades que resultaban funcionales para la organización comunitaria. Los integrantes de los equipos femeninos y masculinos asistían a las competencias interveredales cuyos campeonatos eran publicitados cada semana en el periódico. El deporte era visto no solo como el "aliado para encausar la impulsividad juvenil” (El Campesino, abril 21 de 1985), sino también como un espacio de organización veredal en el que los jóvenes podía crear asociaciones para promover obras comunales.

Las agrupaciones de jóvenes cumplieron una función de gran importancia en los programas de cooperación internacional de la Alianza para el Progreso, aplicados de 1961 a 1970. Una de sus finalidades era crear las condi-

3. La mayoría de ellas constituyen industrias químicas con excepción de Sears, que fue líder en la venta de productos por catálogo. 
ciones adecuadas de organización rural para la reforma agraria, en el contexto de la lucha anticomunista que liberaba Estados Unidos para contrarrestar la influencia de la revolución cubana en el país. Los jóvenes rurales jugaron un papel indispensable en la creación de asociaciones y en la aplicación de las tecnologías de la Revolución verde. Fue así como alrededor de las organizaciones juveniles de $R a-$ dio Sutatenza se llevó a cabo una alianza con el Programa Interamericano para la Juventud Rural del IICA (Instituto Interamericano de Cooperación para la Agricultura, 1961, 1970) y los Cuerpos de Paz.

El programa inició sus labores en Colombia en 1962 y dentro de sus objetivos estaba la creación de asociaciones juveniles en la forma de clubes de amas de casa, clubes de deporte o grupos veredales, todos los cuales eran denominados Clubes 4-S. Los jóvenes prestaban servicio social a sus comunidades y debían promover proyectos productivos tecnificados en las parcelas. Por su parte, el programa y las empresas que financiaban los clubes, ofrecían asistencia técnica, así como herramientas, insumos, semillas y los animales que necesitara cada proyecto. No solo recibían enseñanza en las técnicas de las actividades agropecuarias, sino que también contaban con espacios de encuentro para el entretenimiento, el deporte, el aprendizaje de diversos oficios, la salud, educación sexual que involucraba instrucción sobre la "procreación responsable", el manejo de la vida familiar y la resolución pacífica de los conflictos. Los muchachos de ambos sexos eran invitados a "unirse a los Clubes 4-S"a través de El Campesino:

El joven campesino lleva por dentro el deseo de sobresalir, de tener influencia, de servir para cosas grandes, de ganar bastante plata. Pero muy pocas veces ese joven encuentra el apoyo necesario y oportuno. [...] Los grupos juveniles rurales son asociaciones de muchachos y muchachas que viven en el campo y tienen entre 10 y 25 años. [...] [Los clubes permiten] saber y practicar el manejo de cultivos, de animales y del hogar. Tener la oportunidad de aprender haciendo, por ejemplo a castrar un cerdo, a vacunar una gallina. Saber para qué es mejor un pedazo de tierra, o para qué sirve la caña brava, la guadua, el fique, la hoja de plátano (El Campesino, octubre 6 de 1968).

A lado de las nociones de progreso vinculadas al aumento de la productividad, la obtención de dinero y la higiene, se encontraban también las prescripciones católicas sobre el cuidado de la familia y el matrimonio. La economía y la moral tenían una profunda influencia en los intentos por llevar el progreso a la juventud agraria.

Al tiempo que se creaban los programas pilotos de los Clubes 4-S, se preparaba la llegada a Colombia de los
Cuerpos de Paz como parte de la ayuda internacional. En 1961, con el titular Colombia centro piloto para los cuerpos pro-paz se anunció, la llegada de los voluntarios del nuevo programa promovido por el presidente de los Estados Unidos de ese entonces, John F. Kennedy.

Sesenta y cuatro [dos] ciudadanos norteamericanos procedentes de varias regiones de los Estados Unidos, llegarán próximamente a Colombia con el fin de establecer el primer centro piloto de los "Cuerpos de Voluntarios de Paz". [...] Los grupos contribuirán a desarrollar la ayuda técnica en las diferentes actividades nacionales, especialmente en el campo (El Campesino, julio 23 de 1961).

En octubre de 1961, entre pasos de "bambuco y boogieboogie" y "cohetes de pólvora" se presentó el encuentro y se dieron las manifestaciones de amistad, solidaridad y ayuda conjunta entre los muchachos y seńoritas de los institutos campesinos de Sutatenza y los voluntarios de paz. Después de esta celebración, los jóvenes norteamericanos movidos por la solidaridad con los pueblos del tercer mundo se distribuyeron por las distintas regiones del país y apoyaron las campañas de educación, extensión agrícola y obras de infraestructura en las veredas.

Por primera vez en nuestra historia, se registra un hecho semejante. Sesenta y dos muchachos, casi todos alumnos de universidades, renuncian a las comodidades que tenían en su país y vienen a compartir con nosotros, nuestros trabajos y angustias [...]. Llegan estos jóvenes como mensajeros de la paz. Desean ayudar a construir una Colombia mejor y cumplir la consigna que dio el presidente Kennedy cuando dijo: "Debemos trabajar en el desarrollo de nuevos recursos, en la reforma de los sistemas de la distribución agraria, en organizar mercados comunes, establecer fábricas, diversificar la producción agrícola, construir carreteras, hospitales y sistemas de abastecimiento de aguas, de los cuales depende la continuidad del progreso, y lograr que todos los ciudadanos, obreros, campesinos, empleados y profesionales, compartan por igual el adelanto de las Américas".

Acostumbrado el país a padecer la llegada de los agitadores comunistas rusos, cubanos y criollos, que no están entre nosotros sino para destruir y creando desorden y anarquía, provocan la revolución, no podemos sino celebrar con alborozo la llegada de esta misión de paz, de trabajo y de ayuda Americana (El Campesino, octubre 22 de 1961).

La ayuda norteamericana era presentada como una acción heroica, altruista, desinteresada y llena de sacrificios, a través de la cual el pueblo colombiano lograría los adelantos técnicos del desarrollo. Era abiertamente una misión progresista y anticomunista abarcaba diversos países de África, Asia y América Latina y en Colombia fueron reconocidos desde 1961 hasta 1981 por su apoyo 
a las poblaciones rurales, las campañas de salubridad, la contribución a la construcción de hospitales, escuelas y caminos y la promoción del movimiento de voluntarios. Junto con ellos se crearon los cuerpos de paz colombianos, integrados por jóvenes estudiantes de diferentes universidades de Bogotá -en especial de la Universidad de los Andes-que se desplazaban a las veredas con el fin de ayudar con las labores agrícolas, las obras de infraestructura y la organización comunitaria.

A pesar de que el programa fue presentado como uno de los logros más exitosos de la cooperación internacional por su contribución al progreso de las poblaciones rurales, algunos de los jóvenes norteamericanos de los Cuerpos de Paz fueron acusados de enseñar a la población la forma de procesar la hoja coca para extraer cocaína e iniciar el tráfico de este alcaloide así como de otras drogas. Al respecto, en el libro Genealogías colombianas, Víctor Mosquera Chaux, embajador de Colombia en Washington durante el gobierno de Virgilio Barco afirmó para el diario El Espectador lo siguiente: "Como consecuencia de los Cuerpos de Paz se formó una cadena compuesta por muchos eslabones del tráfico del alcaloide. Naturalmente, se establecieron nuevos cultivos y se agravó el problema” (El Espectador, mayo 11 de 2010).

Por otro lado, el historiador y exconjuez de la Corte Suprema de Justicia Horacio Gómez Aristizábal asevera:

Estos quisieron [...] revelarnos el secreto de la civilización americana. Muy pronto estos jóvenes propagaron la subcultura del narcotráfico [...]. Ya estaban motivados por la gran calidad de la marihuana que se producía en la Guajira [...] se organizó el negocio entre el consumidor del norte y el productor colombiano (García-Hoyos, 2006, p. 42).

En adelante, la producción y tráfico de cocaína se convertiría en uno de los problemas sociales más acuciantes. Desde la perspectiva católica, la droga -"el quinto jinete del apocalipsis" (El Campesino, enero 21 de 1979)- sería la nueva preocupación asociada a los jóvenes. En $E l$ Campesino, las notas informativas y la preocupación por combatir la marihuana -llamada la "hierba maldita" - y la cocaína ocuparían desde mediados de la década de 1970 hasta 1990, las campañas dirigidas a la juventud.

Por su parte, los clubes y programas de líderes locales y su vínculo con los voluntarios foráneos llevaron al campo bienes y servicios que si bien su provisión era un deber del Estado no fueron concebidos como tal, sino como actos de altruismo y sacrificio por parte de las misiones norteamericanas, cuya finalidad en últimas, no era otra que incorporar a la población campesina en los patrones de producción y consumo del capitalismo.

También florecieron otros programas para el progreso y aunque no estuvieron abiertamente dirigidos a los jóvenes rurales, sí fueron ellos quienes participaron con mayor protagonismo. La movilidad hacia las ciudades y los centros de colonización fueron propugnados fuertemente en la década de 1960 y luego drásticamente censurados en los años setenta. La noción del joven aventurero que podía conseguir riqueza fuera de su parcela, contribuyó a una gran movilidad geográfica que llevó a la población joven fuera de las fronteras nacionales.

\section{Migración y colonización}

La migración a las ciudades fue promovida de forma implícita por la educación, las obras de infraestructura y el trabajo en las industrias. Los estudios de Lauchlin Currie de 1950 denunciaban que el problema del agro era el minifundio, por lo tanto el pequeño campesino debía desplazarse a las ciudades para crear una mano de obra apta para el desarrollo industrial (Kalmanovitz \& López, 2006). Parte de las formas de promoción de empresas como Coltejer y Bavaria consistía en la oferta de becas para el desplazamiento de los jóvenes a los centros de educación en las ciudades y su vínculo como trabajadores de la industria. Sin embargo, esta fue una forma de migración controlada comparada con aquellos que llegaron a la ciudad por cuenta propia en busca de formación y oportunidades laborales ya precarias en 1970. En esta década, las campañas contra la migración presentadas por El Campesino denunciaron con mayor vigor las condiciones de miseria de la gente de los campos en la ciudad, buscando con ello desestimular la movilidad de los jóvenes de sus parcelas.

En otra instancia, los colonos de las tierras baldías se constituyeron en una fuente de riqueza para sus familias y la nación misma. Estos ocupaban las primeras páginas de El Campesino y eran vistos como una especie de héroes aventureros que civilizaban las tierras más inhóspitas del país. Colonizar era "hacer patria" y así lo anunciaba el periódico en 1959: "Hombre fuertes con el sudor de su frente conquistaron un trozo de la patria”. Fértiles praderas para engorde de ganado son hoy las selvas de antaño" (El Campesino, agosto 23 de 1959). La colonización ofrecía posibilidades de explotar de manera racional y económica la tierra y contaba con "la anunciada ayuda tanto del Gobierno como de las entidades semioficiales que han ofrecido crédito, asistencia técnica, además de un plan 
tendiente a dotar de vías las zonas que se reincorporen a la economía nacional" (El Campesino, marzo 15 de 1959). Sin embargo, tras la creación del Inderena en 1968, si bien se reconoció la importancia de la productividad de las tierras colonizadas se condenó asimismo el daño ambiental subsecuente, lo cual contribuyó a difundir una imagen del campesino colono como depredador de los recursos naturales.

La conquista de tierras desconocidas se concretó igualmente en un motivo que llevó a los jóvenes campesinos a emigrar al extranjero. El llamado "camino verde" hacia Venezuela fue una forma de migración común hacia el trabajo en las haciendas, el servicio doméstico y el comercio urbano durante la década de 1960. Empero, muchos indocumentados empezaron a ser deportados en la década posterior por considerarse inconveniente la dimensión que había alcanzado el fenómeno. En 1971, un artículo de El Campesino sostenía que Venezuela, un país de ocho millones de habitantes, tenía cerca de un millón de colombianos la mayoría de origen rural. A pesar de su magnitud, esta migración fue tratada como una "invasión pacífica” por el presidente venezolano Caldera:

Los inmigrantes a través del camino verde, a pie, recorren varios kilómetros. Luego salen a las carreteras donde son esperados por vehículos particulares o de servicio público, ya avisados o previamente contratados, para llevarlos a su destino final: una hacienda en la zona rural, o una casa de familia, un bar, un hotel, un parque en la zona urbana [...]. No han hecho una migración ociosa. Ha sido un aporte de mano de obra al desarrollo del país, especialmente en el frente agrícola con resultados satisfactorios [...] los colombianos han trabajado con óptimos rendimientos (El Campesino, febrero 21 de 1971).

Hubo un claro reconocimiento del trabajo de los colombianos en el país venezolano. No obstante, en 1976 habían sido deportados 5.587:

Jóvenes entre 17 y 19 ańos de edad. Gente trabajadora que en su mayoría pertenece al sector agropecuario y de la construcción. Su actitud a la llegada es de completa derrota y frustración [...]. Más del $90 \%$ entró a Venezuela de forma ilegal [...]. En general el deportado no se extrańa por la repatriación. Reconoce estar ilegalmente en Venezuela, pero rechaza la forma como se les agarra en el mismo trabajo; el trato, la intransigencia para no darles la oportunidad de avisar a los suyos, recoger sus pertenencias, traer su dinero, ropa y documentos (El Campesino, febrero 22 de 1976).

El "camino verde" hacia Venezuela fue la vía de mayor impacto en la migración internacional durante las décadas de los sesenta y setenta. En ella se destaca la contradicción entre las condiciones de ilegalidad y el aporte de fuerza de trabajo para la economía del país vecino.

A mediados de siglo se promovió entre los jóvenes rurales el ideal del trabajo duro a cualquier costo. Este iba desde el liderazgo y la creación de empresas hasta la aguerrida aventura a través de la migración y la colonización. Para los jóvenes, la pequeña producción agrícola era insuficiente y debían ambicionar mayores riquezas. Sin embargo, en la década de 1970 el desempleo empezó a convertirse en uno de los mayores problemas que aquejaban la vida en las ciudades. La colonización dejó de ser deseable por ser un factor que ahondaba el conflicto armado y afectaba los recursos del país: "Colonizan pero destruyen los bosques. Inderena pide preservar los recursos" (titular de El Campesino, octubre 5 de 1969). Las migraciones hacia el extranjero empezaron a tener mayor control y un número importante de ellos regresaba al país en calidad de deportados.

Una vez saturada la demanda de fuerza de trabajo, el campesino debía regresar a los campos. Sin embargo, la alta productividad que se había propuesto en la década de 1960 gracias a la revolución verde empezaba a generar problemas. Al finalizar la década de 1970, el alto costo de los insumos, el empobrecimiento de los suelos y el aumento del costo de vida hicieron de las pequeñas parcelas lugares inconsistentes con las aspiraciones de los jóvenes campesinos y condujeron a rendimientos decrecientes en la producción. A pesar de que por mucho tiempo se había promovido la ética del trabajo duro entre los jóvenes, al finalizar la década de 1970 no había un escenario claro donde cumplir ese papel. La desocupación se erigió, entonces, en una problemática destacada entre los jóvenes rurales:

En cada vereda y aldea rurales es creciente el número de jóvenes hombres y mujeres que ya no encuentran en qué ocuparse y para los cuales resultan insuficientes las tradicionales tareas de la agricultura y la ganadería. Como es forzoso una gran parte de esos jóvenes sin oficio se irán a las ciudades este año a tratar de abrirse paso y, desde luego, a agravar los ya graves problemas existentes (El Campesino, enero 11 de 1970).

La juventud rural, que para la década de 1970 no era una población mayoritaria en términos demográficos, empezaba a ser una "juventud olvidada que con menor atención seguía experimentando las antiguas problemáticas" (El Campesino, enero 11 de 1970). Así lo expresa el testimonio de un joven del campo publicado en el periódico: 
[Joven campesino] "Yo no estoy de acuerdo con la violencia pero entiendo muy bien por qué esos compañeros, que fueron mis amigos de la escuela se han ido a la pelea. Ellos querían hacer algo en la vida. Querían que se hablara de ellos, que se les aplaudiera, y no encontraron otra manera de lograrlo que formando una cuadrilla" [...]. [Escritor del artículo] Los jóvenes campesinos no cuentan ni siquiera con una mínima parte del espíritu comprensivo y benevolente que la sociedad en sus relaciones con la juventud de otros sectores. (El Campesino, febrero 15 de 1970).

Este espíritu benevolente no demoraría mucho tiempo en llegar a las zonas rurales a través de El campesino. Tras la creación del ICBF en 1968 como una dependencia de la división de menores del Ministerio de Justicia, se implementaron las políticas hacia la protección de la infancia y la juventud. En las publicaciones del periódico a cargo de esa institución, se dio primero un vigoroso énfasis en la protección de la familia y luego en el cuidado de los niños, los adolescentes y los jóvenes.

Ante la ausencia de trabajo y oficio en las zonas rurales y urbanas, los niños y los jóvenes ya no estaban obligados a trabajar. Los padres debían sacrificarse para hacer que toda la población colombiana llegara a cursar el quinto grado de primaria (El Campesino, octubre 3 de 1971). Además, debían facilitar bienes materiales para crear un ambiente agradable y carińoso que propiciara el buen desarrollo de los menores de edad. Los padres ya no debían esperar que los hijos aportaran económicamente a la familia, sino crear las condiciones adecuadas para transferir a los menores recursos para su futuro. Debían aprender a fabricar juguetes, celebrar fiestas y dar caramelos para cuidar la inocencia de los niños. También recibían instrucción por medio de talleres para fabricar diferentes objetos que necesitaban los menores: "hágale un escritorio a su nińo"; "un bolso para sus hijos"; el "tocador económico para el dormitorio de las jovencitas". Y la "moda juvenil, los bordados, la blusa y la jardinera para las jovencitas” (El Campesino, enero 22 de 1978). Estos consejos prácticos ayudaban a los padres a comunicarse mejor con sus hijos y comprenderlos, sobre todo en la adolescencia. Al tiempo, surgen explicaciones psicológicas que instruyen a los padres acerca de las conductas de un adolescente a fin de poder tratarlo:

La adolescencia comienza con la pubertad y termina cuando cesa el crecimiento [...] Es el periodo más importante y más delicado. Pone de manifiesto las tendencias más opuestas. Así, por ejemplo, a una energía excesiva sigue un periodo de depresión y pereza; a una energía desbordante sucede una profunda melancolía. (El Campesino, abril 7 de 1968).

La depresión, la pereza, la melancolía, la energía desbordante aparecen en el semanario y en los discursos sobre la juventud como la expresión de la condición biológica y natural del adolescente y no como el resultado de las condiciones sociales y económicas en las que se lleva a cabo su proceso de socialización.

El Campesino se consagró también como un apoyo para entender las implicaciones legales de esta fase del desarrollo humano. En 1970 y 1971 la norma delimitó esta población y surgió la obligatoriedad de la tarjeta de identidad para todas las personas entre los siete y los veintiún años de edad. Durante toda la década se publicaron en varias oportunidades los derechos del niño (concepto que abarcaba a los menores de edad, incluidos los adolescentes y los jóvenes).

A pesar de que la ley objetaba el trabajo de los menores, la transformación de los mensajes de las publicaciones no fue radical. Durante la década de 1970 y los primeros años 1980 convivían en El Campesino las publicaciones que alababan a los niños y a los adolescentes trabajadores con las que buscaban alejarlos y protegerlos del mundo laboral. Otras campañas promovían el cuidado especial a los menores en el trabajo y proponían el uso del calzado en el trabajo, el cambio de las cuńas para encavar las herramientas y el uso de madera lisa y sin astillas para los cabos de las palas y las picas que iban a ser utilizadas por los menores. Sin embargo, a mediados de la década de 1980 las tareas agrícolas eran vistas como peligrosas y podían configurar una forma de maltrato. El mismo grupo poblacional que en 1959 era congregado en "hogares" y "granjas infantiles" autosuficientes para que aprendieran a producir sus medios de subsistencia y evitar su vagancia (El Campesino, agosto 19 de 1959), veinte años más tarde tendría proscrito el trabajo agrícola y debía permanecer en la escuela.

La no obligatoriedad del trabajo agrícola entre los jóvenes rurales y las continuas ofertas y posibilidades educativas por fuera de las zonas rurales contribuyeron a desarrollar la idea de libertad en la elección de un oficio o vocación. A principios de la década de 1960 el mayor dilema que debían enfrentar los jóvenes rurales era saber si su vocación se inclinaba a la vida familiar o a la vida religiosa. En los años setenta, a este dilema se sumaba la existencia de múltiples posibilidades educativas en las que, no obstante, el joven rural entraba en desventaja y desigualdad de oportunidades frente a los jóvenes de las ciudades.

Ante la carencia de una infraestructura educativa para los mayores de doce años que permanecían en las zonas rurales, la formación se enfocó en los programas técnicos y en los consejos para la vida íntima y familiar. Las cam- 
pañas para prevenir la drogadicción empezaron a ser cada vez más numerosas y se crearon programas para el control de la natalidad. Las drogas y el sexo se presentaban como problemáticas juveniles por excelencia.

El interés sobre el control de la natalidad lo habían propuesto los mismos jóvenes campesinos en la década de 1960 a través de cartas. En ellas preguntaban sobre el consentimiento de la Iglesia respecto al uso de anticonceptivos y la respuesta obvia de las autoridades eclesiales sostenía que los preceptos de la Santa Sede no los avalaban. En la década de 1970 el amor fue presentado como el antídoto para la concepción irresponsable. La paciente espera por el amor verdadero, por la mujer o el hombre ideales, el respeto a la virginidad y los valores católicos, debían retardar la iniciación de la sexualidad. Fueron los programas del ICBF de forma independiente y en contra las restricciones de la Iglesia, los que promoverían el uso de anticonceptivos entre los campesinos.

En las zonas rurales la educación primaria había logrado una amplia cobertura. La escuela nueva, contemplada en el plan decenal de 1959 a 1969, facilitaba la educación básica a través de cursos multigrado (Colbert 1999; Caro 1981). Una infraestructura educativa adecuada permitía congregar a los niños en la educación y alejarlos del trabajo, lo cual no ocurrió con los mayores de doce años. El énfasis laboral desaparecía paulatinamente, pero paralelo a ello no existía una infraestructura educativa para los años de adolescencia y juventud en las zonas rurales.

Se amplió el acceso a la educación a través de la creación de internados, bachilleratos técnicos, comerciales y vocacionales agrícolas y agropecuarios. Empero, quienes deseaban continuar sus estudios más allá del quinto año, debían desvincularse de sus redes familiares y sociales para acceder a los internados y colegios localizados en su mayoría en las áreas urbanas (Silva, 2009).

Sin una infraestructura adecuada para la educación en las zonas rurales, las escuelas radiofónicas, los institutos campesinos y el Sena ${ }^{4}$ ofrecían cursos y programas técnicos semipresenciales a distancia o por correspondencia. A la par de la disminución de la poca oferta ocupacional en el campo, los programas de educación rural de Acción Cultural Popular desde 1948 a 1990 y el Sena, a partir de 1956, crearon programas de instrucción. La primera buscó ampliar el conocimiento de los campesinos en salud, economía, trabajo y moral a través de la educación no formal y la alfabetización generalizada sin generar un desplazamiento de las zonas rurales (además del perfeccionamiento técnico de los cultivos y producciones pecuarias, promovía la construcción de huertas caseras, modistería, artesanías y ebanistería) y a partir de 1954 se centró en la formación de líderes. Se trataba de una formación más bien paralela, no equivalente a la educación escolar y no era un requisito para acceder a las becas de los institutos campesinos.

Por su parte, el Sena creó una estructura de cursos cortos y ocupaciones técnicas (no necesariamente dirigidos a los jóvenes) a fin de que por un lado, la población perfeccionara por medio de la higiene, la maquinaria y la eficiencia de las labores tradicionales de la población campesina y por el otro, accediera a los oficios propios de la industria a través de los cuales se favorecía la migración a las ciudades.

En el ámbito agropecuario, el Sena creó cursos muy variados, algunos de los cuales se sobreponían a las labores que los campesinos ya dominaban gracias al conocimiento empírico, como el programa de formación de gañanes, la tecnología del cultivo del maíz y la yuca, el cultivo de la huerta casera, el manejo y almacenamiento de granos, la cestería y el telar manual para la elaboración de telas de fique. Otros como el manejo de suelos, fertilizantes y maquinaria agrícola, hacían énfasis en la adopción de tecnología. Finalmente, se organizaron un gran número de cursos que facilitaban la articulación de los aprendices como trabajadores urbanos. Oficios como contabilidad, auxiliar de droguería, mecanotaquigrafía, panadería, pastelería, albañilería, enchape, soldadura, fundición, cables e instalaciones eléctricas, pintura de muros, pintura de brocha sobre superficies de madera, programa de formación de vitrinista, instalación de acabados de vidrio, instalación de vinilos y alfombras e instalaciones hidráulicas y sanitarias, eran aprendidos por toda la población, pero no podían ser desempeñados en las zonas rurales.

El cumplimiento de los programas no necesariamente garantizaba el acceso a las redes institucionales y sociales que facilitaran la consecución de empleos ni la obtención de mayores recursos económicos para quienes permanecían en el campo, así como tampoco lo hiciera la formación técnica para las zonas urbanas. La democratización de la educación había copado la demanda de mano de obra menos calificada y generado una mayor exigencia en la capacitación de empleados profesionales (Díez de Medina, 2001; Durston, 2001). Las restricciones para acceder al mercado y el aumento del consumo por parte

4. Institución creada en 1956 por iniciativa de la Unión de Trabajadores de Colombia para la Capacitación Obrera (Sena 2011). 
de la población campesina, dio lugar a un proceso de descapitalización de las zonas rurales que se tornaría más crítico con la apertura económica de la década de 1990 (Suárez, 2007).

Se había difundido una noción de juventud ajena a las reales condiciones de las zonas rurales. El acceso a la educación formal no estaba garantizado, el trabajo juvenil era muestra de una situación de "desventaja" y el ocio continuaba siendo condenado en términos morales. No había un lugar claro para esta población. Ir a la ciudad, colonizar, buscar oportunidades en el extranjero o incluso permanecer en la vereda para trabajar o practicar un ocio forzado, implicaba un riesgo en la consecución de los medios materiales para subsistir. En 1980 se creó un vacío en el papel ocupacional de los jóvenes campesinos al pasar de un periodo de migración y articulación de la fuerza de trabajo rural al capitalismo industrial, a una fase de segregación y promoción del retorno a las zonas rurales.

\section{Consideración final}

El análisis acerca de las formas de intervención en el núcleo de la población rural juvenil durante la segunda mitad del siglo XX, revela una historia de distribución diferencial de derechos dentro de la nación colombiana. En este proceso, la creación de una ciudadanía segmentaria o dual (Torres, 1998; Holston, 2008) basada en la distribución diferencial de derechos entre poblaciones específicas, se enmascara bajo el protagonismo laboral del campesino para el desarrollo del país.

Estas formas de intervención se centraron en la transformación de las maneras de producción y reproducción social. Acción Cultural Popular buscó no solo convertir a los campesinos en protagonistas en la vida del país, sino también plantear las vías del progreso familiar, agrario y nacional.

Además del fomento de la tecnología, el control de la población, los recursos, la industrialización y el desarrollo agrícola, en el contexto del desarrollo existía "una serie de factores ligados a consideraciones culturales, como la educación y la necesidad de fomentar valores culturales modernos" (Escobar, 2007, p. 87). De esta forma, el subdesarrollo y la necesidad de progreso pasaron a formar parte de la identidad de las poblaciones rurales y en el argumento para sustentar las relaciones de control y dependencia entre las llamadas naciones del tercer mundo y las desarrolladas (Gupta, 1998).
Los programas civilizatorios sirven de estrategia para legitimar la segregación social de los campesinos a partir de la atribución de una función principalmente económica. Bajo los programas de desarrollo, los jóvenes son conducidos a la productividad como héroes que se sacrificaban por la patria. El heroísmo y la moral del trabajo duro funcionan como estrategias de subjetivación o gubernamentalidad (Foucault, 1999) para crear un aporte o reserva de fuerza de trabajo. En las formas de intervención descritas sobre la juventud rural, la culpa del atraso personal, familiar y nacional recae sobre el campesino y pasa a ser un mecanismo para delegar los problemas estructurales de una nación sobre unos sujetos particulares y así legitimar su exclusión.

\section{Referencias}

Banco de la República (2012). Radio Sutatenza: puntos de partida para una historia. Boletín cultural y bibliográfico. Volumen XLVI, Número 82.

Bernal, H. (2005). Radio Sutatenza. De la realidad a la utopía. Bogotá: Fundación Cultural Javeriana.

Caro, A. (1981). Educación rural en Colombia 1960-1980. Un primer análisis. Tesis de pregrado, no publicada. Bogotá: Universidad Nacional de Colombia.

Colbert, V. (1999). Mejorando el acceso y la calidad de la educación para el sector rural pobre. El caso de la Escuela Nueva en Colombia. Revista Iberoamericana de Educación, 20, 107-136.

Díez de Medina, R. (2001). Jóvenes y empleo en los noventa. OIT: Cinterfor.

Durston, J. (2001). Juventud rural y desarrollo en América Latina. Estereotipos y realidades. En Donás Burak, Solum (comp.). Adolescencia y juventud en América Latina (pp. 325-340). Cartago: LUR. Pp.

El Espectador (mayo 11 de 2010). "Vuelven los Cuerpos de Paz a Colombia".

Escobar, A. (2007). La invención del tercer mundo. Construcción y deconstrucción del desarrollo. Bogotá: Norma.

Fajardo, D. (1981). El Estado y la formación del campesinado en el siglo XIX. Bogotá: Historia y Sociedad.

Fals-Borda, O. (1961). Campesinos de los Andes. Estudio sociológico de Saucio. Bogotá: Punta de Lanza.

Fals-Borda, O. (1975). Historia de la cuestión agraria en Colombia. Bogotá: Rosca.

Foucault, M. (1999): La gubernamentalidad. En Estética, ética y hermenéutica. Obras esenciales (Volumen III, pp. 175-197). Barcelona: Paidós.

$62<$ Universidad de San Buenaventura, Cali - Colombia 
García-Hoyos, J. C. (2006). De la coca a la cocaina. Bogotá: Universidad del Rosario.

Gupta, A. (1998). Postcolonial Developments: Agriculture in the Making of Modern India. Durham: Duke University Press

Guzmán, G., Fals-Borda, O., \& Umaña, E. (2005). La violencia en Colombia. Bogotá: Taurus.

Holston, J. (2008). Insurgent Citizenships. Disjunctions of democracy and modernity in Brazil. New Jersey: Princenton University Press.

IICA (1961). Informe del seminario interamericano de líderes de juventudes rurales. San José de Costa Rica: Ministerio de Agricultura y Ganadería.

IICA (1970). Programa Interamericano para la Juventud Rural. San José de Costa Rica: Ministerio de Agricultura y Ganadería.

Johnston, B., \& Mellor, J. (1962). "El papel de la agricultura en el desarrollo económico". El Trimestre Económico, 29, 279-304.

Kalmanovitz, S. \& López, E. (2006). La agricultura colombiana en el siglo XX. Bogotá: Fondo de Cultura Económica.

Muñoz, D. (2007). Concepciones de niñez y juventud en las pedagogías católicas de principios del siglo XX. Revista Latinoamericana de Ciencias Sociales, 5(2), 841-857.
OIT (1973). Convenio sobre la edad minima.

Ortiz, F. (1973). El contrapunteo cubano del tabaco y el azúcar. Barcelona: Ariel.

Parra, R. \& Zubieta, L. (1983). Escuela, marginalidad y contextos sociales en Colombia. Bogotá: Universidad Pedagógica Nacional.

Sánchez, G. (1977). Las ligas campesinas en Colombia. Bogotá: Ediciones Alcaraván.

Silva, N. (2009). Los labradores del azar. Un estudio sobre las representaciones y dinámicas de la juventud rural. Maguaré 23, 471-509.

Suárez, A. (2007). El modelo agrícola colombiano y los alimentos en la globalización. Bogotá: Ediciones Aurora.

Torres, C. A. (1998). Educación, clase social y doble ciudadanía: los dolores de parto del multiculturalismo en América Latina. Perfiles educativos, 81. Recuperado de http://www. redalyc.org/pdf/132/13208102.pdf.

Vera de Flachs, M. C. (2006). Reformas, contrarreformas y movimientos estudiantiles en la Universidad de Córdoba. En R. Marsiske, \& L. Alvarado. Movimientos estudiantiles en América Latina. México: Cesu-UNAM. 